\title{
The Association of the Lymphocyte-to-C-Reactive-Protein Ratio With Gastric Cancer Patients Who Receive Curative Treatment
}

\author{
TORU AOYAMA ${ }^{1,2^{*}}$, MASATO NAKAZANO $^{1,2^{*}}$, SHINSUKE NAGASAWA ${ }^{1,2}$, KENTARO HARA $^{1,2}$, \\ KEISUKE KOMORI ${ }^{1}$, HIROSHI TAMAGAWA ${ }^{1}$, YUKIO MAEZAWA ${ }^{1,2}$, KENKI SEGAMI $^{1,2}$, \\ KAZUKI KANO ${ }^{1}$, TAKASHI OGATA ${ }^{2}$, NORIO YUKAWA ${ }^{1}$, YASUSHI RINO ${ }^{1}$ and TAKASHI OSHIMA ${ }^{1,2}$ \\ ${ }^{1}$ Department of Surgery, Yokohama City University, Yokohama, Japan; \\ ${ }^{2}$ Department of Gastrointestinal Surgery, Kanagawa Cancer Center, Yokohama, Japan
}

\begin{abstract}
Background/Aim: We investigated the association of the preoperative lymphocyte-to-C-reactive-protein ratio (LCR) with gastric cancer survival and recurrence after curative treatment. Patients and Methods: This study included 480 patients who underwent curative surgery followed by adjuvant treatment for gastric cancer between 2013 and 2017. The prognostic factors for overall survival (OS) and recurrence-free survival (RFS) were identified. Results: A LCR of 7,000 was regarded as the optimal critical point of classification, considering the 1-, 3-and 5-year survival rates. The OS rates at 3 and 5 years after surgery were $84.4 \%$ and $73.9 \%$ in the low-LCR group, respectively, and $92.4 \%$ and $87.0 \%$ in the high$L C R$ group, respectively, and were statistically significantly different. The RFS rates at 3 and 5 years after surgery were $78.8 \%$ and $68.7 \%$ in the low-LCR group, respectively, and $89.3 \%$ and $86.6 \%$ in the high-LCR group, respectively, with a statistically significant difference. A multivariate analysis showed that the LCR was a significant independent prognostic factor for both OS and RFS. Conclusion: The LCR was a significant prognostic factor for survival in patients who underwent curative treatment for gastric cancer.
\end{abstract}

Gastric cancer is the third-most common cancer and the second leading cause of cancer-related death in the world. Every year, 1 million new cases of gastric cancer occur, with 800,000 gastric cancer deaths noted worldwide $(1,2)$. Gastrectomy with

This article is freely accessible online.

*These Authors contributed equally to this study.

Correspondence to: Toru Aoyama, Department of Gastrointestinal Surgery, Kanagawa Cancer Center, 2-3-2 Nakao, Asahi-ku, Yokohama 241-8515, Japan. Tel: +81 457872800, e-mail: taoyama@lilac.plala.or.jp

Key Words: Gastric cancer, lymphocyte, C-reactive protein, survival.
D2 lymphadenectomy with or without perioperative adjuvant treatment is a global standard treatment for resectable gastric cancer. However, even when patients receive curative treatment, more than half develop recurrence (3-5). Once recurrence manifests after curative treatment, the prognosis is limited (6, 7). Thus, to further improve patients' chances of a survival, it is necessary to establish new approaches for treatment.

Recently, various studies have demonstrated that tumor cells directly and/or directly affect host inflammatory cells. These host inflammatory cells promote tumor growth by various means, such as regulating the promotion of angiogenesis or cytokine activity and inhibiting apoptosis $(8,9)$. In addition, an elevated inflammatory response due to tumor cell activity during the perioperative period was also related to poor oncological outcomes in gastrointestinal cancer $(10,11)$. Various systemic inflammation markers have been tested to establish optimal systemic inflammation markers. Among them, the lymphocyte-to-C-reactive-protein ratio (LCR) is a particularly promising marker of systemic inflammation in the perioperative period $(12,13)$. Recent studies on the LCR in solid tumors have shown that a low LCR is associated with a poor survival in many tumors, including gastrointestinal tumors, with a trend toward an association between a low LCR and a worse overall survival (OS) being greater for metastatic than non-metastatic disease. However, while the LCR is an inflammatory- and immunologic-based score evaluated in gastrointestinal cancers, few studies have evaluated its prognostic value in patients with gastric cancer $(14,15)$.

In the present study, we investigated whether or not OS and recurrence-free survival (RFS) associated with the LCR of gastric cancer patients who underwent curative surgery followed by adjuvant chemotherapy.

\section{Patients and Methods}

Patients. Patients were selected based on the medical records of consecutive patients who underwent curative resection for gastric cancer at Kanagawa Cancer Center from 2013 to 2017. The 
Table I. Patient characteristics.

\begin{tabular}{|c|c|c|c|c|}
\hline Characteristics & $\begin{array}{l}\text { No. of patients }(\%) \\
\qquad(\mathrm{n}=480)\end{array}$ & $\begin{array}{l}\text { Lymphocyte C-reactive protein } \\
\text { Albumin ratio }<7,000 \text { group } \\
\qquad(\mathrm{n}=90)\end{array}$ & $\begin{array}{l}\text { Lymphocyte C-reactive protein } \\
\text { Albumin ratio }>7,000 \text { group } \\
\qquad(\mathrm{n}=390)\end{array}$ & $p$-Value \\
\hline Age (years) & & & & 0.041 \\
\hline$<65$ & $144(30.0 \%)$ & $19(21.1 \%)$ & $125(32.0 \%)$ & \\
\hline$\geq 65$ & $336(70.0 \%)$ & $71(78.9 \%)$ & $265(68.0 \%)$ & \\
\hline Gender & & & & 0.115 \\
\hline Man & $318(66.3 \%)$ & $66(73.3 \%)$ & $252(66.3 \%)$ & \\
\hline Woman & $162(33.7 \%)$ & $24(26.7 \%)$ & $138(33.7 \%)$ & \\
\hline Pathological type & & & & 0.027 \\
\hline Intestinal & $243(50.6 \%)$ & $55(61.1 \%)$ & $188(49.4 \%)$ & \\
\hline Diffuse & $237(49.4 \%)$ & $35(38.9 \%)$ & $202(50.6 \%)$ & \\
\hline UICC T status & & & & 0.007 \\
\hline $\mathrm{T} 1$ & $300(62.5 \%)$ & $45(50.0 \%)$ & $255(67.1 \%)$ & \\
\hline $\mathrm{T} 2$ to $\mathrm{T} 3$ & $180(37.5 \%)$ & $45(50.0 \%)$ & $135(32.9 \%)$ & \\
\hline Lymph node metastasis & & & & 0.021 \\
\hline Negative & $346(72.1 \%)$ & $56(62.2 \%)$ & $290(76.3 \%)$ & \\
\hline Positive & $134(27.9 \%)$ & $34(37.8 \%)$ & $100(23.7 \%)$ & \\
\hline Lymphatic invasion & & & & 0.102 \\
\hline Negative & $333(69.4 \%)$ & $56(62.2 \%)$ & $277(72.9 \%)$ & \\
\hline Positive & $147(30.6 \%)$ & $34(37.8 \%)$ & $113(27.1 \%)$ & \\
\hline Vascular invasion & & & & 0.189 \\
\hline Negative & $275(57.3 \%)$ & $46(51.1 \%)$ & $229(60.3 \%)$ & \\
\hline Positive & $205(42.7 \%)$ & $44(48.9 \%)$ & $161(39.7 \%)$ & \\
\hline Postoperative complications & & & & 0.246 \\
\hline Yes & $67(14.0 \%)$ & $16(17.8 \%)$ & $51(13.4 \%)$ & \\
\hline No & $413(86.0 \%)$ & $74(82.2 \%)$ & $339(86.6 \%)$ & \\
\hline
\end{tabular}

UICC: Union for International Cancer Control.

inclusion criteria were as follows: 1) histologically proven adenocarcinoma, 2) clinical stage I to III disease as evaluated using the 15 th edition of the general rules for gastric cancer published by the Japanese Gastric Cancer Association (16), and 3) complete (R0) resection of gastric cancer with radical lymph node dissection.

Surgical procedure and adjuvant treatment. All of the patients received distal or total gastrectomy with lymphadenectomy. D1+nodal dissection was performed for clinical stage IA disease, while D2 dissection was performed for clinical stage $\geq$ IB. Patients diagnosed with pathological II or III disease received adjuvant chemotherapy for one year. In principle, patients with pathological stage II disease received S-1 monotherapy, while those with pathological stage III disease received S-1 plus docetaxel or capecitabine+oxaliplatin therapy.

Follow-up. Hematological tests and physical examinations were performed at least every three months for five years. The carcinoembryonic antigen and CA19-9 tumor marker levels were checked at least every three months for five years. Patients underwent computed tomography (CT) every 6-12 months until 5 years after surgery.

Evaluations and statistical analyses. The significance of differences between the LCRs and clinicopathological parameters was determined using the $\chi^{2}$ test. The Kaplan-Meier method was used to calculate the OS and RFS curves. Univariate and multivariate survival analyses were performed using a Cox proportional hazards model. $p$-Values of $<0.05$ were considered to indicate statistical significance. The SPSS software program (v27.0 J Win; SPSS, Chicago, IL, USA) was used for all statistical analyses. This study was approved by the IRB of Kanagawa Cancer Center.

\section{Results}

Patients. We evaluated 480 patients in the present study. The median age was 68 years (range $=32-90$ years), and 318 patients were male, while 162 were female. Based on the 3 and 5-year OS rates and previous studies, we set the cut-off value for LCR at 7,000 in the present study. On comparing the background characteristics between patients with LCR $<7,000$ (low-LCR group) and LCR $\geq 7,000 \mathrm{mg} / \mathrm{dl}$ (high-LCR group), significant differences were noted in the age, pathological type, clinical $\mathrm{T}$ status, and $\mathrm{N}$ status. The incidence rates of elderly patients and aggressive tumors were much higher in the low-LCR group compared to the high-LCR group (Table I).

Survival analyses and recurrence patterns. Each clinicopathological factor was categorized as shown in Table II and analyzed for its prognostic significance. Univariate analyses 
Table II. Uni- and Multi-variate Cox proportional hazards analysis of clinicopathological factors for overall survival.

\begin{tabular}{|c|c|c|c|c|c|c|c|}
\hline \multirow[b]{2}{*}{ Factors } & \multirow[b]{2}{*}{ No } & \multicolumn{3}{|c|}{ Univariate analysis } & \multicolumn{3}{|c|}{ Multivariate analysis } \\
\hline & & OR & $95 \% \mathrm{CI}$ & $p$-Value & OR & $95 \% \mathrm{CI}$ & $p$-Value \\
\hline Age (years) & & & & 0.362 & & & \\
\hline$<65$ & 144 & 1.000 & & & & & \\
\hline$\geq 65$ & 336 & 1.309 & $0.733-2.338$ & & & & \\
\hline Gender & & & & 0.360 & & & \\
\hline Woman & 318 & 1.000 & & & & & \\
\hline Man & 162 & 1.294 & $0.745-2.248$ & & & & \\
\hline Pathological type & & & & 0.140 & & & \\
\hline Intestinal & 243 & 1.000 & & & & & \\
\hline Diffuse & 237 & 1.472 & $0.881-2.460$ & & & & \\
\hline UICC T status & & & & 0.050 & & & 0.056 \\
\hline $\mathrm{T} 1-\mathrm{T} 2$ & 300 & 1.000 & & & 1.000 & & \\
\hline $\mathrm{T} 3-\mathrm{T} 4$ & 180 & 1.892 & $0.999-3.582$ & & 1.845 & $0.0984-3.459$ & \\
\hline Lymph node metastasis & & & & $<0.001$ & & & $<0.001$ \\
\hline Negative & 336 & 1.000 & & & 1.000 & & \\
\hline Positive & 134 & 2.927 & $1.603-5.344$ & & 2.872 & $1.643-5.027$ & \\
\hline $\begin{array}{l}\text { Lymphocyte C-reactive protein } \\
\text { Albumin ratio }\end{array}$ & & & & 0.044 & & & 0.031 \\
\hline$>7,000$ & 390 & 1.000 & & & 1.000 & & \\
\hline$<7,000$ & 90 & 1.704 & $1.011-2.873$ & & 1.764 & $1.053-2.957$ & \\
\hline Lymphatic invasion & & & & 0.929 & & & \\
\hline Negative & 333 & 1.000 & & & & & \\
\hline Positive & 147 & 1.144 & $0.647-2.022$ & & & & \\
\hline Vascular invasion & & & & 0.021 & & & 0.013 \\
\hline Negative & 275 & 1.000 & & & 1.000 & & \\
\hline Positive & 205 & 2.089 & $1.108-3.936$ & & 2.167 & $1.177-3.992$ & \\
\hline Postoperative complications & & & & 0.384 & & & \\
\hline Yes & 67 & 1.000 & & & & & \\
\hline No & 413 & 1.374 & $0.673-2.805$ & & & & \\
\hline
\end{tabular}

UICC: Union for International Cancer Control.

for the OS showed that the pathological $\mathrm{T}$ factor, pathological $\mathrm{N}$ factor, vascular invasion, and LCR were significant prognostic factors. The LCR was therefore selected for the final multivariate analysis model. The OS rates at 3 and 5 years after surgery were $84.4 \%$ and $73.9 \%$ in the low-LCR group, respectively, and $92.4 \%$ and $87.0 \%$ in the high-LCR group, respectively, and were statistically significantly different $(p=0.031)$. The OS curves are shown in Figure 1. Univariate analyses for the RFS showed that the LCR was a significant prognostic factor. It was thus selected as a significant prognostic factor for the final multivariate analysis model (Table III). The RFS rates at 3 and 5 years after surgery were $78.8 \%$ and $68.7 \%$ in the low-LCR group, respectively, and $89.3 \%$ and $86.6 \%$ in the high-LCR group, respectively, and were statistically significantly different $(p=0.048)$. The RFS curves are shown in Figure 2. The site of first relapse differed significantly between the high- and low-LCR groups (Table IV). The incidence of peritoneal recurrence was significantly higher in the low-LCR group compared to the high-LCR group.
Postoperative adjuvant chemotherapy course and recurrence patterns in the high-and low-LCR groups. On comparing the postoperative course between the high- and low-LCR groups, there were some differences in the postoperative adjuvant chemotherapy course and incidence of postoperative surgical complications. In the present study, 27.3\% (131/480) of patients needed postoperative adjuvant chemotherapy. Among them, 35.6\% (32/90) needed postoperative adjuvant chemotherapy in the low-LCR group, while $25.4 \%$ (99/390) needed it in the high-LCR group $(p=0.05)$. The introduction rate of postoperative adjuvant chemotherapy differed between the two groups. Among the patients who required postoperative adjuvant chemotherapy, only $65.6 \%(21 / 32)$ received it in the low-LCR group, while $86.9 \%(86 / 99)$ received it in the high-LCR group $(p=0.007)$. In addition, on comparing the details of surgical complications, the incidence of abdominal abscess was significantly higher, and ileus tended to be higher, in the low-LCR group compared to the high-LCR group. Indeed, the incidence of abdominal abscess was $7.8 \%$ in the low-LCR group and $2.8 \%$ in the 


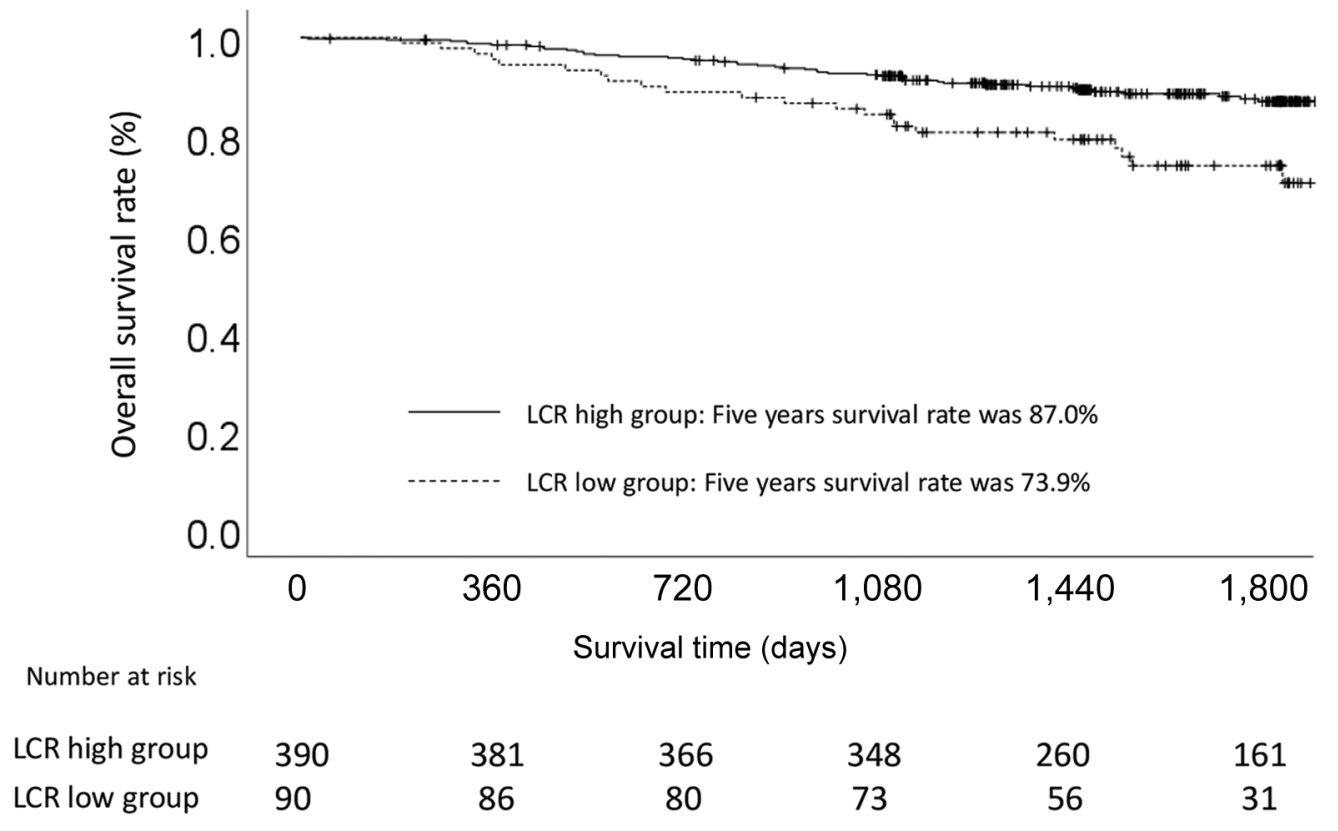

Figure 1. A comparison of the overall survival in patients with a lymphocyte-to-C-reactive-protein ratio of $>$ 7,000 and $\leq 7,000$.

Table III. Uni- and Multi-variate Cox proportional hazards analysis of clinicopathological factors for recurrence-free survival.

\begin{tabular}{|c|c|c|c|c|c|c|c|}
\hline \multirow[b]{2}{*}{ Factors } & \multirow[b]{2}{*}{ No } & \multicolumn{3}{|c|}{ Univariate analysis } & \multicolumn{3}{|c|}{ Multivariate analysis } \\
\hline & & OR & $95 \% \mathrm{CI}$ & $p$-Value & OR & $95 \% \mathrm{CI}$ & $p$-Value \\
\hline Age (years) & & & & 0.152 & & & \\
\hline$<65$ & 144 & 1.000 & & & & & \\
\hline$\geq 65$ & 336 & 1.470 & $0.868-2.491$ & & & & \\
\hline Gender & & & & 0.0524 & & & \\
\hline Woman & 162 & 1.000 & & & & & \\
\hline Man & 318 & 1.178 & $0.712-1.946$ & & & & \\
\hline Pathological type & & & & 0.257 & & & \\
\hline Intestinal & 243 & 1.000 & & & & & \\
\hline Diffuse & 237 & 1.313 & $0.820-2.103$ & & & & \\
\hline UICC $\mathrm{T}$ status & & & & 0.094 & & & 0.049 \\
\hline $\mathrm{T} 1-\mathrm{T} 2$ & 300 & 1.000 & & & 1.000 & & \\
\hline $\mathrm{T} 3-\mathrm{T} 4$ & 180 & 1.669 & $0.916-3.042$ & & 1.786 & $1.007-3.181$ & \\
\hline Lymph node metastasis & & & & 0.001 & & & $<0.001$ \\
\hline Negative & 336 & 1.000 & & & 1.000 & & \\
\hline Positive & 134 & 2.530 & $1.449-4.418$ & & 2.685 & $1.601-4.503$ & \\
\hline Lymphocyte C-reactive protein & & & & 0.040 & & & 0.048 \\
\hline Albumin ratio & & & & & & & \\
\hline$\geq 7,000$ & 390 & 1.000 & & & 1.000 & & \\
\hline$<7,000$ & 90 & 1.683 & $1.024-2.765$ & & 1.634 & $1.004-2.658$ & \\
\hline Lymphatic invasion & & & & 0.652 & & & \\
\hline Negative & 333 & 1.000 & & & & & \\
\hline Positive & 147 & 1.133 & $0.658-1.952$ & & & & \\
\hline Vascular invasion & & & & 0.052 & & & 0.034 \\
\hline Negative & 275 & 1.000 & & & 1.000 & & \\
\hline Positive & 205 & 1.770 & $0.995-3.149$ & & 1.824 & $1.047-3.177$ & \\
\hline Postoperative complications & & & & 0.567 & & & \\
\hline Yes & 67 & 1.000 & & & & & \\
\hline No & 413 & 1.208 & $0.633-2.305$ & & & & \\
\hline
\end{tabular}




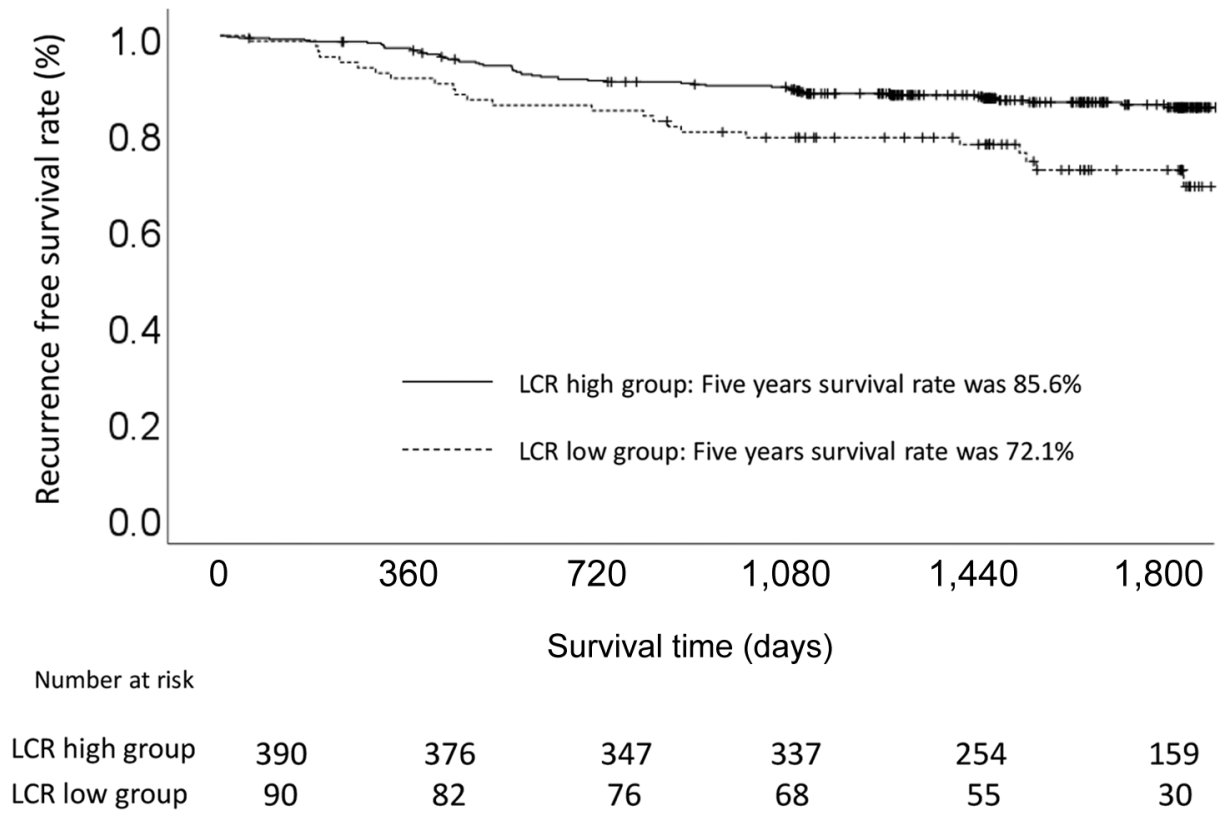

Figure 2. A comparison of the recurrence-free survival in patients with a lymphocyte-to-C-reactive-protein ratio of $>$ 7,000 and $\leq 7,000$.

Table IV. Patterns of recurrence between the patients with lymphocyte $C$-reactive protein albumin ratio $<7,000$ and those with lymphocyte $C$ reactive protein albumin ratio $\geq 7,000$.

\begin{tabular}{|c|c|c|c|c|c|c|c|}
\hline \multirow[b]{3}{*}{ Recurrence site } & & & \multicolumn{4}{|c|}{ Lymphocyte C-reactive protein albumin ratio } & \multirow[b]{3}{*}{$p$-Value } \\
\hline & \multicolumn{2}{|c|}{$\begin{array}{l}\text { All cases } \\
(\mathrm{n}=480)\end{array}$} & \multicolumn{2}{|c|}{$\begin{array}{l}<7,000 \\
(\mathrm{n}=90)\end{array}$} & \multicolumn{2}{|c|}{$\begin{array}{l}\geq 7,000 \\
(\mathrm{n}=390)\end{array}$} & \\
\hline & Number & $\%$ & Number & $\%$ & Number & $\%$ & \\
\hline Peritoneal & 22 & $4.6 \%$ & 8 & $8.9 \%$ & 14 & $3.6 \%$ & 0.030 \\
\hline Hematological & 15 & $3.2 \%$ & 4 & $4.4 \%$ & 11 & $2.8 \%$ & 0.474 \\
\hline Lymph node & 10 & $2.1 \%$ & 1 & $1.1 \%$ & 9 & $2.3 \%$ & 0.425 \\
\hline Local site & 9 & $1.8 \%$ & 1 & $1.1 \%$ & 8 & $2.1 \%$ & 0.553 \\
\hline Total & 56 & & 14 & & 42 & & \\
\hline
\end{tabular}

high-LCR group $(p=0.016)$, and the incidence of ileus was $4.4 \%$ in the low-LCR group and $1.7 \%$ in the high-LCR group $(p=0.082)$.

\section{Discussion}

The present study explored whether or not the LCR had clinical influence on the OS and RFS in patients who received curative gastrectomy followed by adjuvant treatment. The major finding was that LCR was an independent prognostic factor for both the OS and RFS. In addition, the LCR was closely related to the postoperative adjuvant treatment course and postoperative surgical complications. Thus, the LCR was considered a promising clinical prognostic marker for patients who received curative treatment for gastric cancer.

In the present study, the hazard ratio (HR) of the LCR for OS was 1.764 [95\% confidence interval $(\mathrm{CI})=1.053-2.957$, $p=0.031]$, and that for the RFS was $1.634(95 \% \mathrm{CI}=1.004-$ $2.658, p=0.048)$. Similar results were observed in previous studies $(12,17)$. Cheng et al. evaluated whether or not the preoperative LCR was a predictor in 607 gastric cancer patients (17). Among them, 294 patients were assigned to the low-LCR group and 313 to the high-LCR group. The 5year OS was $80.5 \%$ in the high-LCR group and $54.9 \%$ in the low-LCR group $(p<0.001)$. In the multivariate analysis, 
they showed that a high LCR was associated with a significantly better OS than a low LCR $(\mathrm{HR}=0.545$, $95 \% \mathrm{CI}=0.372-0.799, p=0.002)$. They concluded that the preoperative LCR was a predictive marker for OS in gastric cancer patients who received curative treatment. In addition, Okugawa et al. also clarified the clinical influence of the preoperative LCR in 477 colorectal cancer patients (12). They showed that a low LCR was a significant prognostic factor for the overall mortality (colon cancer: $H R=2.21$, 95\% $\mathrm{CI}=1.03-4.74, p=0.04$ and rectal cancer: $\mathrm{HR}=2.22$, $95 \% \mathrm{CI}=1.14-4.32, p=0.018)$ and cancer-specific mortality (colon cancer: $\mathrm{HR}=2.04,95 \% \mathrm{CI}=1.00-4.19, p=0.05$ and Rectal cancer: $\mathrm{HR}=2.25,95 \% \mathrm{CI}=1.12-4.50, p=0.022)$. They concluded that the preoperative LCR was a useful marker for both the preoperative and postoperative management of colorectal cancer patients. Given these findings, the LCR might be a cost-effective and broadly available prognostic marker for gastric cancer patients who have received curative treatment.

Regarding why the LCR influenced the survival of patients with gastrointestinal cancer, including gastric cancer, there are several possible explanations. First, there might be a relationship between the LCR and postoperative surgical complications. In the present study, the incidence of abdominal abscess and ileus was higher in the low-LCR group compared to the high-LCR group. Similar results were observed in previous studies. Cheng et al. evaluated the relationship between the LCR and postoperative surgical complications in 607 gastric cancer patients (17). They found that there was a significant relationship between the LCR and postoperative surgical complications. The incidence of postoperative surgical complications was $20.4 \%$ in the lowLCR group and $12.1 \%$ in the high-LCR group, showing a significant difference $(p=0.006)$. In addition, Okugawa et al. evaluated the relationship between the LCR and postoperative surgical complications in 477 colorectal cancer patients (12). They also found that there was a significant relationship between the LCR and postoperative surgical complications. The incidences of postoperative infectious complications, surgical site infection and remote infection were significantly higher in the low-LCR group than in the high-LCR group (postoperative infectious complications: $p=0.0007$, surgical site infection: $p=0.01$, and remote infection: $p=0.021$ ). Furthermore, a low LCR was an independent risk factor for postoperative complications in colorectal cancer patients (odds ratio $=1.91,95 \% \mathrm{CI}=1.07-3.07, p=0.028$ ). Second, there might be a relationship between the LCR and adjuvant chemotherapy introduction in gastric cancer patients. We found that the LCR influenced the introduction of postoperative adjuvant chemotherapy and recurrence pattern. In the low-LCR group, $35 \%$ of patients needed postoperative adjuvant chemotherapy, with only $65 \%$ of them receiving adjuvant chemotherapy. In contrast, in the high-LCR group, only $25 \%$ of patients needed postoperative adjuvant chemotherapy, with nearly $90 \%$ receiving adjuvant chemotherapy. Therefore, the benefits of adjuvant chemotherapy were limited in the low-LCR group. In addition, the difference in the introduction of adjuvant chemotherapy affected the recurrence patterns. Indeed, the rate of peritoneal recurrence was significantly higher in the lowLCR group compared to the high-LCR group, and pivotal previous studies showed similar results. For example, the ACTS-GC trial, which tested the usefulness and efficacy of S1 adjuvant chemotherapy for locally advanced gastric cancer, showed that effective adjuvant chemotherapy significantly suppressed and reduced the rate of peritoneal recurrence (18). The actual rates of peritoneal recurrence were $11.2 \%$ in the adjuvant treatment group and $15.8 \%$ in the surgery-alone group in the ACTS-GC trial ( $p=0.009)$. These findings suggest that the LCR influenced the introduction of adjuvant chemotherapy, and decreased chemotherapy introduction affected the pattern of recurrence and prognosis. While there might be a clinical relationship between the LCR and immunological response, chemotherapy response and postoperative surgical complication occurrence, the mechanism involved is unclear. Thus, future studies should focus on this issue.

The cut-off value of the LCR was 7,000 in the present study. We set this cut-off at the median LCR value. To apply the LCR to the clinical setting in gastric cancer treatment, it is necessary to find and set the optimal cut-off value. Previous studies have set cut-off values of the LCR in gastrointestinal cancer. Cheng et al. evaluated the clinical influence of the LCR in 607 gastric cancer patients who received curative surgery between 2013 and 2019 (17). In their study, the LCR was calculated as the lymphocyte count (number/l)/C-reactive protein (CRP) (mg/l). According to the receiver operating characteristics curve, they set the cut-off value at 0.63 . Okugawa et al. evaluated the clinical influence of the LCR in 477 colorectal cancer patients who received curative surgery (12). They set the cut-off value at 6,000 using a receiver operating characteristics curve. In addition, Okugawa et al. evaluated the clinical influence of the LCR in 551 gastric cancer patients (18). In their study, the LCR was calculated as the lymphocyte count (number/1)/CRP $(\mathrm{mg} / \mathrm{l})$. The cut-off value of lymphocytes was $1 \times 10^{9} / 1$, and that of CRP was $3.0 \mathrm{mg} / 1$. Differences in the cut-off value of the LCR might be due to patients' background characteristics, perioperative treatment or the number of patients. Further studies are needed in order to establish the optimal method for evaluating the LCR and the optimal LCR cut-off value in gastric cancer patients.

Several limitations associated with the present study warrant mention. First, the present study was a retrospective analysis conducted at a single institution. Thus, there might have been selection bias in the patients in this series. Second, the timing of the evaluation of the LCR was not 
standardized. We evaluated the LCR on preoperative days 1 to 7 . This timing bias might have affected the present study results. Given the above limitations, the present results must be confirmed in another cohort.

In conclusion, the preoperative LCR was found to be a significant prognostic and/or predictive factor for gastric cancer patients who received gastrectomy and adjuvant treatment. The preoperative LCR is a promising and potentially useful tool for developing treatment strategies to optimize the treatment of gastric cancer patients.

\section{Conflicts of Interest}

The Authors declare no conflicts of interest in association with the present study.

\section{Authors' Contributions}

TA and MN made substantial contributions to the concept and design. TA, MN, KS, SN, HS, KK, TY, IH, HW, MN, HT, TO, NY, TO and YR made substantial contributions to the acquisition of data and the analysis and interpretation of data. TA, HW, MN, HT, TO, NY and YR were involved in drafting the article or revising it critically for important intellectual content. TA, NM, KK and TO gave their final approval of the version to be published.

\section{Acknowledgements}

This work was supported by JSPS KAKENHI Grant Number $21 \mathrm{~K} 08688$.

\section{References}

1 Smyth EC, Nilsson M, Grabsch HI, van Grieken NC and Lordick F: Gastric cancer. Lancet 396(10251): 635-648, 2020. PMID: 32861308. DOI: 10.1016/S0140-6736(20)31288-5

2 Bray F, Ferlay J, Soerjomataram I, Siegel RL, Torre LA and Jemal A: Global cancer statistics 2018: GLOBOCAN estimates of incidence and mortality worldwide for 36 cancers in 185 countries. CA Cancer J Clin 68(6): 394-424, 2018. PMID: 30207593. DOI: $10.3322 /$ caac.21492

3 Japanese Gastric Cancer Association: Japanese classification of gastric carcinoma: $3^{\text {rd }}$ English edition. Gastric Cancer 14(2): 101112, 2011. PMID: 21573743. DOI: 10.1007/s 10120-011-0041-5

4 Smyth EC, Verheij M, Allum W, Cunningham D, Cervantes A, Arnold D and ESMO Guidelines Committee: Gastric cancer: ESMO Clinical Practice Guidelines for diagnosis, treatment and follow-up. Ann Oncol 27(suppl 5): v38-v49, 2016. PMID: 27664260. DOI: 10.1093/annonc/mdw350

5 NCCN. NCCN Clinical Practice Guidelines in Oncology. Available at: https://www.nccn.org/professionals/physician_gls/ default.aspx [Last accessed on October 31, 2021]

6 Janjigian YY, Shitara K, Moehler M, Garrido M, Salman P, Shen L, Wyrwicz L, Yamaguchi K, Skoczylas T, Campos Bragagnoli A, Liu T, Schenker M, Yanez P, Tehfe M, Kowalyszyn R, Karamouzis MV, Bruges R, Zander T, Pazo-Cid R, Hitre E, Feeney K, Cleary JM, Poulart V, Cullen D, Lei M, Xiao H,
Kondo K, Li M and Ajani JA: First-line nivolumab plus chemotherapy versus chemotherapy alone for advanced gastric, gastro-oesophageal junction, and oesophageal adenocarcinoma (CheckMate 649): a randomised, open-label, phase 3 trial. Lancet 398(10294): 27-40, 2021. PMID: 34102137. DOI: 10.1016/S0140-6736(21)00797-2

7 Chung HC, Bang YJ, S Fuchs C, Qin SK, Satoh T, Shitara K, Tabernero J, Van Cutsem E, Alsina M, Cao ZA, Lu J, Bhagia P, Shih CS and Janjigian YY: First-line pembrolizumab/placebo plus trastuzumab and chemotherapy in HER2-positive advanced gastric cancer: KEYNOTE-811. Future Oncol 17(5): 491-501, 2021. PMID: 33167735. DOI: 10.2217/fon-2020-0737

8 Grivennikov SI, Greten FR and Karin M: Immunity, inflammation, and cancer. Cell 140(6): 883-899, 2010. PMID: 20303878. DOI: 10.1016/j.cell.2010.01.025

9 Balkwill $\mathrm{F}$ and Mantovani A: Inflammation and cancer: back to Virchow? Lancet 357(9255): 539-545, 2001. PMID: 11229684. DOI: $10.1016 / \mathrm{S} 0140-6736(00) 04046-0$

10 Kano K, Aoyama T, Maezawa Y, Hayashi T, Yamada T, Tamagawa H, Sato T, Cho H, Yoshikawa T, Rino Y, Masuda M, Oshima $\mathrm{T}$ and Ogata T: Postoperative level of C-reactive protein is a prognosticator after esophageal cancer surgery with perioperative steroid therapy and enhanced recovery after surgery care. In Vivo 33(2): 587-594, 2019. PMID: 30804146. DOI: 10.21873 /invivo.11515

11 Hara K, Aoyama T, Yamada T, Nakazono M, Nagasawa S, Shimoda Y, Kumazu Y, Numata M, Hayashi T, Tamagawa H, Shiozawa M, Morinaga S, Yukawa N, Rino Y, Masuda M, Ogata $\mathrm{T}$ and Oshima $\mathrm{T}$ : The prognostic value of the perioperative systemic inflammation score for patients with advanced gastric cancer. Anticancer Res 40(3): 1503-1512, 2020. PMID: 32132050. DOI: 10.21873/anticanres.14095

12 Okugawa Y, Toiyama Y, Yamamoto A, Shigemori T, Ide S, Kitajima T, Fujikawa H, Yasuda H, Hiro J, Yoshiyama S, Yokoe T, Saigusa S, Tanaka K, Shirai Y, Kobayashi M, Ohi M, Araki T, McMillan DC, Miki C, Goel A and Kusunoki M: Lymphocyte-C-reactive protein ratio as promising new marker for predicting surgical and oncological outcomes in colorectal cancer. Ann Surg 272(2): 342-351, 2020. PMID: 32675548. DOI: $10.1097 /$ SLA.0000000000003239

13 Okugawa Y, Toiyama Y, Oki S, Ide S, Yamamoto A, Ichikawa T, Kitajima T, Fujikawa H, Yasuda H, Saigusa S, Hiro J, Yoshiyama S, Kobayashi M, Araki $\mathrm{T}$ and Kusunoki M: Feasibility of assessing prognostic nutrition index in patients with rectal cancer who receive preoperative chemoradiotherapy. JPEN J Parenter Enteral Nutr 42(6): 998-1007, 2018. PMID: 29786882. DOI: 10.1002/jpen.1041

14 Okugawa Y, Toiyama Y, Fujikawa H, Ide S, Yamamoto A, Omura Y, Yin C, Kusunoki K, Kusunoki Y, Yasuda H, Yokoe T, Hiro J, Ohi M and Kusunoki M: Prognostic potential of lymphocyte-Creactive protein ratio in patients with rectal cancer receiving preoperative chemoradiotherapy. J Gastrointest Surg 25(2): 492502, 2021. PMID: 32040814. DOI: 10.1007/s11605-019-04495-4

15 Lu LH, Zhong C, Wei W, Li SH, Mei J, Zou JW, Guo RP and Zhang YF: Lymphocyte-C-reactive protein ratio as a novel prognostic index in intrahepatic cholangiocarcinoma: A multicentre cohort study. Liver Int 41(2): 378-387, 2021. PMID: 32562336. DOI: $10.1111 /$ liv.14567

16 Japanese Gastric Cancer Association: Japanese classification of gastric carcinoma: 3rd English edition. Gastric Cancer 14(2): 
101-112, 2011. PMID: 21573743. DOI: 10.1007/s10120-0110041-5

17 Cheng CB, Zhang QX, Zhuang LP and Sun JW: Prognostic value of lymphocyte-to-C-reactive protein ratio in patients with gastric cancer after surgery: a multicentre study. Jpn J Clin Oncol 50(10): 1141-1149, 2020. PMID: 32564084. DOI: 10.1093/jjco/hyaa099

18 Okugawa Y, Toiyama Y, Yamamoto A, Shigemori T, Ichikawa T, Yin C, Suzuki A, Fujikawa H, Yasuda H, Hiro J, Yoshiyama S, Ohi M, Araki T, McMillan DC and Kusunoki M: Lymphocyte-
to-C-reactive protein ratio and score are clinically feasible nutrition-inflammation markers of outcome in patients with gastric cancer. Clin Nutr 39(4): 1209-1217, 2020. PMID: 31155370. DOI: 10.1016/j.clnu.2019.05.009

Received October 8, 2021

Revised November 2, 2021

Accepted November 3, 2021 